\title{
Update on Intradialytic Cardiac Dysfunction
}

DOI:

10.1111/sdi.12532

\section{Document Version}

Accepted author manuscript

Link to publication record in Manchester Research Explorer

\section{Citation for published version (APA):}

Odudu, A., \& Mclntyre, C. W. (2016). Update on Intradialytic Cardiac Dysfunction. Seminars in Dialysis. https://doi.org/10.1111/sdi.12532

\section{Published in:}

Seminars in Dialysis

\section{Citing this paper}

Please note that where the full-text provided on Manchester Research Explorer is the Author Accepted Manuscript or Proof version this may differ from the final Published version. If citing, it is advised that you check and use the publisher's definitive version.

\section{General rights}

Copyright and moral rights for the publications made accessible in the Research Explorer are retained by the authors and/or other copyright owners and it is a condition of accessing publications that users recognise and abide by the legal requirements associated with these rights.

\section{Takedown policy}

If you believe that this document breaches copyright please refer to the University of Manchester's Takedown Procedures [http://man.ac.uk/04Y6Bo] or contact uml.scholarlycommunications@manchester.ac.uk providing relevant details, so we can investigate your claim.

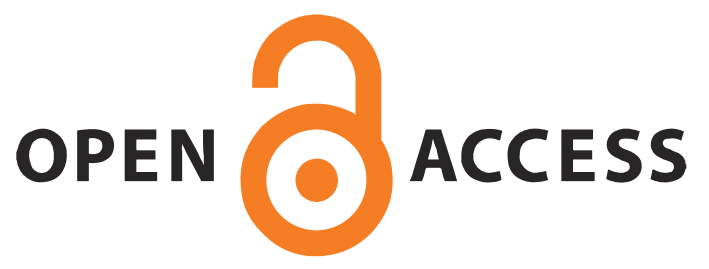




\section{Update on Intradialytic Cardiac Dysfunction}

Aghogho Odudu MBChB, $\mathrm{PhD}^{1,2}$ and Christopher W McIntyre MBBS, $\mathrm{DM}^{3}$

${ }^{1}$ Insititute of Cardiovascular Sciences, University of Manchester, United Kingdom, ${ }^{2}$ Salford

Royal Hospital, Salford, United Kingdom and ${ }^{3}$ Division of Nephrology, Schulich School of Medicine and Dentistry, University of Western Ontario, London, Canada

Address for correspondence:

Dr Aghogho Odudu

University of Manchester

Institute of Cardiovascular Sciences

Core Technology Facility

46 Grafton Street

Oxford Road

Manchester

Email: a.odudu@manchester.ac.uk

Tel.: +44 (0) 1612751189

This is the pre-peer reviewed version of the following article: Update on Intradialytic Cardiac Dysfunction, Seminars in Dialysis-2016, which has been published in final form at DOI: 10.1111/sdi.12532. This article may be used for non-commercial purposes in accordance with Wiley Terms and Conditions for Self-Archiving. 


\section{Abstract}

Cardiac dysfunction is a key factor in the high morbidity and mortality rates seen in hemodialysis (HD) patients. Much of the dysfunction is manifest as adverse changes in cardiac and vascular structure prior to commencing dialysis. This adverse vascular remodeling arises as a dysregulation between pro- and anti-proliferative signaling pathways in response to hemodynamic and non-hemodynamic factors. The HD procedure itself further promotes cardiomyopathy by inducing hypotension and episodic regional cardiac ischemia that precedes global dysfunction, fibrosis, worsening symptoms and increased mortality. Drug-based therapies have been largely ineffective in reversing HD-associated cardiomyopathy, in part due to targeting single pathways of low yield. Few studies have sought to establish natural history and there is no framework of priorities for future clinical trials. Targeting intra-dialytic cardiac dysfunction by altering dialysate temperature, composition or ultrafiltration rate might prevent the development of global cardiomyopathy, heart failure and mortality through multiple pathways. Novel imaging techniques show promise in characterizing the physiological response to HD that is a unique model of repetitive ischemia-reperfusion injury. Reducing HD-associated cardiomyopathy may need a paradigm shift from empirical delivery of solute clearance to a personalized therapy balancing solute and fluid removal with microvascular protection. This review describes the evidence for intra-dialytic cardiac dysfunction outlining cardioprotective strategies that extend to multiple organs with potential impacts on exercise tolerance, sleep, cognitive function and quality of life. 


\section{Introduction}

It is established for twenty years that there is a stepwise increase in mortality with advancing stages of Chronic Kidney Disease (CKD) and that cardiovascular disease is the major cause of death. It is further recognized that there is a graded transition from atherosclerotic causes of death in early-stage CKD to non-atherosclerotic events in end-stage kidney disease patients using HD or peritoneal dialysis (1). Drug-based therapies that reduce atherosclerotic risks in those with predialysis CKD, have reduced or no proven benefit in those using HD. Trials of drug therapies directed at novel CKD-specific risk factors have yet to make a measurable impact. Several drugs that completely attenuated experimental uremic cardiomyopathy, had no detectable effects in the clinical setting. A myopic focus on drug-based interventions might fail on several levels by:

i) An incomplete understanding of natural history

ii) Operating too late in the natural history to reverse pathology

iii) Addressing low-yield, single pathway targets rather than high-yield final common pathways

HD-associated cardiomyopathy results from adverse changes in cardiac and vascular structure and function in early-stage CKD compounded by the repeated injury that the HD procedure can impose. Intra-dialytic cardiac dysfunction is characterized by transient episodes of cardiac ischemia, regional ventricular dysfunction and intra-dialytic hypotension that precedes global cardiac dysfunction and increased mortality. This mirrors the cascade of cardiac ischemia. We recently proposed that as repetitive HD-induced cardiac dysfunction further accelerates adverse cardiac remodeling, the term HD-associated cardiomyopathy be used to distinguish the separate effects of pre-dialysis CKD. Intra-dialytic cardiac dysfunction may underlie the sharp increase in mortality in the first year of commencing HD (2). Past and current studies seek to characterize the adverse effects of HD in other vulnerable vascular beds such as the gut, brain 
and kidney $(3,4)$. An emerging picture casts conventional HD as a unique model of a repetitive multi-organ ischemia-reperfusion injury. This might be the driving factor in excessive adverse events as diverse as post-dialysis fatigue, sleep dysregulation, loss of residual renal function, stroke, depression, cognitive impairment and exercise intolerance (5).

\section{Priming factors of CKD-associated cardiomyopathy}

In the clinical setting rather than animal models, the term CKD-associated cardiomyopathy is more precise than 'uremic' as the cardiomyopathy is detectable in the earliest stages of CKD, prior to the onset of uremic symptoms. CKD-associated cardiomyopathy is macroscopically characterized by abnormalities in cardiac geometry and function. Most commonly described are Left Ventricular (LV) dilation, Left Ventricular Hypertrophy (LVH) and systolic dysfunction as determined by non-invasive cardiac imaging. The prevalence of LVH increases with advancing stage of CKD. A cross-sectional analysis of the Chronic Renal Insufficiency Cohort Study reported LVH prevalence of $32 \%, 48 \%, 57 \%$, and $75 \%$ for estimated GFR categories $\geq 60,45$ to 59,30 to 44 , and $<30 \mathrm{ml} / \mathrm{min} / 1.73 \mathrm{~m}^{2}$, respectively (6). A longitudinal study of 300 patients reported a one year increase in prevalence of LVH from $40 \%$ to $49 \%$ for a $2 \mathrm{ml} / \mathrm{min}$ annual decline in estimated GFR (7). The LV mass-to-volume ratio indexes LV wall thickness to cavity size, categorizing LV geometry as concentric remodeling, concentric hypertrophy or eccentric hypertrophy. The type of geometry has been noted to prognosticate cardiovascular risk beyond that by LVH alone in CKD and HD patients $(8,9)$. More recent studies using novel techniques, have extended the definition of CKD-associated cardiomyopathy using measures of regional abnormalities in motion (10). At a cellular level, myocyte hypertrophy is an adaptive response to several stimuli that normalize ventricular wall stress despite abnormal LV pressure or volume load to maintain cardiac output. Cardiac growth in adolescence, pregnancy, and athletes are examples of adaptive physiological hypertrophy in health. Continuation of these driving factors allows a maladaptive process with promotion of extracellular matrix deposition, capillary apoptosis and rarefaction. Capillary 
rarefaction is not easily visualized but impairs coronary flow reserve by shortening diastolic coronary refill time and limiting the ability to increase blood flow in response to metabolic demand. Thus a vicious cycle ensues inexorably leading to cardiac fibrosis. The diverse causes of LV remodeling and hypertrophy are traditionally categorized by hemodynamics. Volume-dependent (preload) factors such as salt and fluid loading lead to myocyte lengthening and eccentric remodeling. Pressure-dependent (afterload) factors such as aortic stiffness and hypertension tend towards cell thickening and concentric remodeling. Such a categorization might oversimplify the complex interactions of LV remodeling prior to the superimposition of intermittent HD. An alternative view describes LV remodelling as the result of an imbalance between proliferative and anti-proliferative factors (11). Proliferative factors are further categorized as hemodynamic, neurohormonal, metabolic, inflammatory and CKD-specific. The latter framework highlights several pressure and volume independent treatment targets to reduce adverse remodeling.

\section{Hemodynamic causes of $L V$ remodeling}

Anemia causes LV remodeling by limiting tissue oxygenation, with adaptive increases in cardiac output, sympathetic nervous system activation and subsequent volume overload. Several major randomized trials in CKD failed to demonstrate cardiovascular benefits of correcting anemia with erythropoiesis stimulating agents (ESAs) with an excess of adverse events in some (12). Posthoc analyses suggested regression of LV mass by ESAs might be restricted to a subgroup with severe anemia undergoing partial correction. Volume overload is a potent cause of eccentric LV remodeling and hypertension, particularly in HD. Treatment of hypertension had mixed results in HD patients with concerns over the U-shaped association between blood pressure and mortality, the optimal timing of blood pressure measurement and a paucity of randomized clinical trials (RCTs) (13). It is widely accepted that addressing hypervolemia antecedes use of antihypertensives for blood pressure control. Higher interdialytic weight gains and ultrafiltration 
volumes are independently associated with high cardiovascular mortality whilst volume control has achieved regression of $\mathrm{LVH}$ and reduced anti-hypertensive use. Volume control in HD is challenging with risks of microvascular injury when probing for dry weight by simple clinical assessment (14). This balance might be achieved by modern techniques to estimate volume status. A study of bioimpedance guided prescription of dry weight in 52 HD patients reduced hypertension in the subgroup of hypervolemic patients whilst reducing intradialytic adverse events by $73 \%$ in a subclinically hypovolemic group (15).

\section{Non-hemodynamic causes of LV remodeling and fibrosis}

There is abundant evidence for LV remodeling independent of volume and blood pressure (16). Correcting hypertension incompletely attenuates LVH and not fibrosis in animal models (17). Insulin resistance was the major determinant of LVH in a study of patients with early stage polycystic kidney disease (18). Insulin signaling and the Akt pathway is also strongly implicated in experimental uremic cardiomyopathy, characterized by a switch to a fetal type of energy utilization from glucose to fatty acids, enhancing susceptibility to ischemia-reperfusion injury (19). Clinical studies targeting the Akt pathway might be a promising novel approach to prevent CKDassociated cardiomyopathy. Increasing evidence implicates endothelial dysfunction as a key factor in myocyte hypertrophy (20). A small RCT reported allopurinol regressed LV mass, restored endothelial function and reduced arterial stiffness in early-stage CKD (21). Myocardial nitric oxide bioavailability forms a major anti-hypertrophic brake through anti-proliferative and anti-apoptotic actions (11). High levels of asymmetric dimethylarginine (ADMA) in CKD reduce nitric oxide bioavailability causing remodelling and myocardial dysfunction through multiple pathways (22, 23). Drugs which increase cyclic guanosine monophosphate within cardiomyocytes have antihypertrophic effects (24). Recent studies have highlighted the role of locally generated cardiotonic steroids and fibroblast growth factor 23 in LV remodelling, both of which have high levels in HD patients $(25,26)$. In particular, sodium can induce adrenal secretion of cardiotonic 
steroids to produce myocyte hypertrophy independent of hemodynamics, highlighting a novel mechanism by which dietary or dialysate sodium modulation might regress LVH in HD patients (27). Reduced cardiotonic steroid production rather than blood pressure reduction might be the mechanism by which aldosterone antagonism with spironolactone reduced LV mass by $14 \mathrm{~g}$ in a 114 patient RCT in early-stage CKD patients (28).

\section{Intra-dialytic cardiac dysfunction}

Experimental and clinical data show that transiently applied coronary ischemia causes regional reductions in LV wall motion that persists for hours after the return of normal perfusion, before eventual functional recovery. This post-ischemic LV dysfunction is known as myocardial stunning and represents a form of ischemia-reperfusion injury (29). Repetitive episodes of ischemia are cumulative and eventually lead to hibernation and cardiac fibrosis (30). It is increasingly appreciated that the process of HD itself causes myocardial ischemia. Early evidence may have been intra-dialytic ischemic electrocardiographic changes and hypotension reported since the 1980s $(31,32)$. Whilst highly prevalent and plausibly linked in the ischemic cascade, the studies lacked direct evidence of reduced myocardial perfusion during HD. A proof-of-concept study found a $30 \%$ reduction in myocardial blood flow during HD by positron emission tomography in the absence of coronary stenosis (33) with these findings subsequently replicated by others (34). Simultaneous 2D-echocardiography (2D-echo) at peak-stress (225 mins into a HD session) compared to pre-HD, showed that the ventricular regions with wall motion abnormalities matched the regions with the greatest reductions in perfusion (33). This validated use of motion abnormalities as practical surrogates for perfusion in subsequent studies. In our natural history study of 70 patients, significant myocardial stunning during HD was noted at baseline in $64 \%$ of patients (35). At one year, mortality was significantly greater in those with stunning at baseline. Among survivors, the LV ejection fraction was markedly lower at rest and during HD. Patients 


\section{Odudu and McIntyre}

showing cardiac stunning by this same definition had greater levels of gut derived endotoxin and more frequent arrhythmias (36). Other investigators showed similar findings with $27 \%$ prevalence of intra-dialytic wall motion abnormalities and increased one year mortality associated with this finding (37). Multivariable analysis showed the significant determinants of these wall motion abnormalities were age, serum troponin-T concentration, frequency of intra-dialytic hypotension and ultrafiltration volumes (35). LV diastolic function also worsens during HD. A study performing serial 2D-echo in 109 HD patients showed systolic and diastolic LV dysfunction occurs as early as 60 minutes into HD before significant ultrafiltration has occurred $(37,38)$. This suggests that intra-dialytic LV dysfunction cannot entirely be explained by volume removal and may not entirely be addressed by reducing ultrafiltration rate. Inflammation may also play a role. A cross-sectional study of 105 patients explored the interaction of inflammatory cytokine profiles with intra-dialytic cardiac dysfunction (39). The group with intra-dialytic LV dysfunction ( $n=29,27 \%$ ) had greater baseline levels of inflammatory cytokines than those without. There was an incremental relationship between the baseline level of inflammatory cytokines and the extent of regional intradialytic LV dysfunction. Serial inflammatory cytokines increased during the HD session, although the increase was similar between the subgroups with and without intra-dialytic dysfunction.

The contribution of atherosclerotic coronary artery disease to intra-dialytic dysfunction is not known. Certainly, the strands of evidence suggest that intra-dialytic dysfunction is not merely a manifestation of undiagnosed coronary artery stenosis. Although the numbers studied were small we demonstrated reductions in myocardial blood flow during HD in patients with normal coronary angiography (33). It is also well recognized that LVH and aortic stiffness reduce coronary flow reserve in the absence of coronary artery stenosis (40). Similar reductions in perfusion under hemodynamic stress with normal coronary arteries are an archetypal featue of any disorder associated with a stiff LV or aorta such as aortic stenosis. Children with CKD are characterized by non-atherosclerotic cardiac and vascular alterations (41). A study of 12 children using HD 
showed high ultrafiltration rates, frequent intradialytic hypotension with $11(92 \%)$ demonstrating intra-dialytic LV dysfunction by wall-motion abnormalities (42). Finally, large studies of stress cardiac perfusion imaging showed an incremental effect of CKD on cardiovascular mortality amongst patients with coronary artery disease excluded by normal perfusion imaging even after adjustment for multiple cardiac abnormalities including LV mass (43). Further work continues to characterize the nature of intra-dialytic cardiac dysfunction.

Novel cardiac imaging methods as a marker of HD-associated cardiomyopathy

Cardiac magnetic resonance (CMR) imaging has greater volumetric accuracy and precision than 2D-echo which tends to overestimate LV mass in CKD (44). Due to load-dependency and reliance on geometric assumptions, LV mass index by $2 \mathrm{D}$-echo may change by $26 \mathrm{~g} / \mathrm{m}^{2}$ across a HD session compared to CMR (45). 2D-echo remains essential for dynamic and repeated imaging during HD where CMR is impractical. 3D-echo studies in HD are anticipated as they potentially combine the volumetric precision of CMR with the practicality of bedside assessment. CMR will remain the reference standard technique for myocardial tissue characterisation as novel noncontrast techniques allow measurement of cardiac fibrosis, oedema, oxygenation and perfusion $(46,47)$. The most widely used index of systolic LV dysfunction remains LV ejection fraction. Ejection fraction infers LV systolic function of cardiac tissue by summation of endocardial borders but lacks information on regional function or cardiac tissue characterization. Lateral LV wall motion abnormalities detect circumferential myocardial fiber contraction but this captures only one vector and cannot distinguish passive motion of tethered tissue. In normal function the myocardium undergoes a complex change of shape (deformation or strain) that largely stems from myocardial fiber orientation in a double helical arrangement (48). This allows a twisting motion and diastolic suction that is essential to efficient energy expenditure (analogous to wringing a towel). Both 2D-echo and CMR allow quantification of longitudinal, circumferential and 
torsional strains throughout systole and diastole using speckle-tracking and tagging respectively. Strain differentiates active from passive motion and determines longitudinal fiber contraction that is an early marker of dysfunction due to cardiac ischemia affecting longitudinal sub-endocardial layers first in a wavefront manner (Figure 1) (49). We recently characterized HD-associated cardiomyopathy using strain determined from serial CMR images tagged with a grid pattern (50). This identified intra-ventricular dyssynchrony and regional reductions in circumferential systolic and diastolic strain distinct from other cardiomyopathies. Two recent studies in CKD and HD show global LV longitudinal systolic strain has incremental prognostic information to ejection fraction $(51,52)$. Another study recently used multivariable regression to report that aortic stiffness by pulse wave velocity and LV mass by 2D-echo, displaced global LV longitudinal strain as independent predictors of mortality in HD patients (53). With the caveats of observational studies, this lends support to a rationale that drugs or HD modification that reduce aortic stiffness may reduce HD-associated cardiomyopathy.

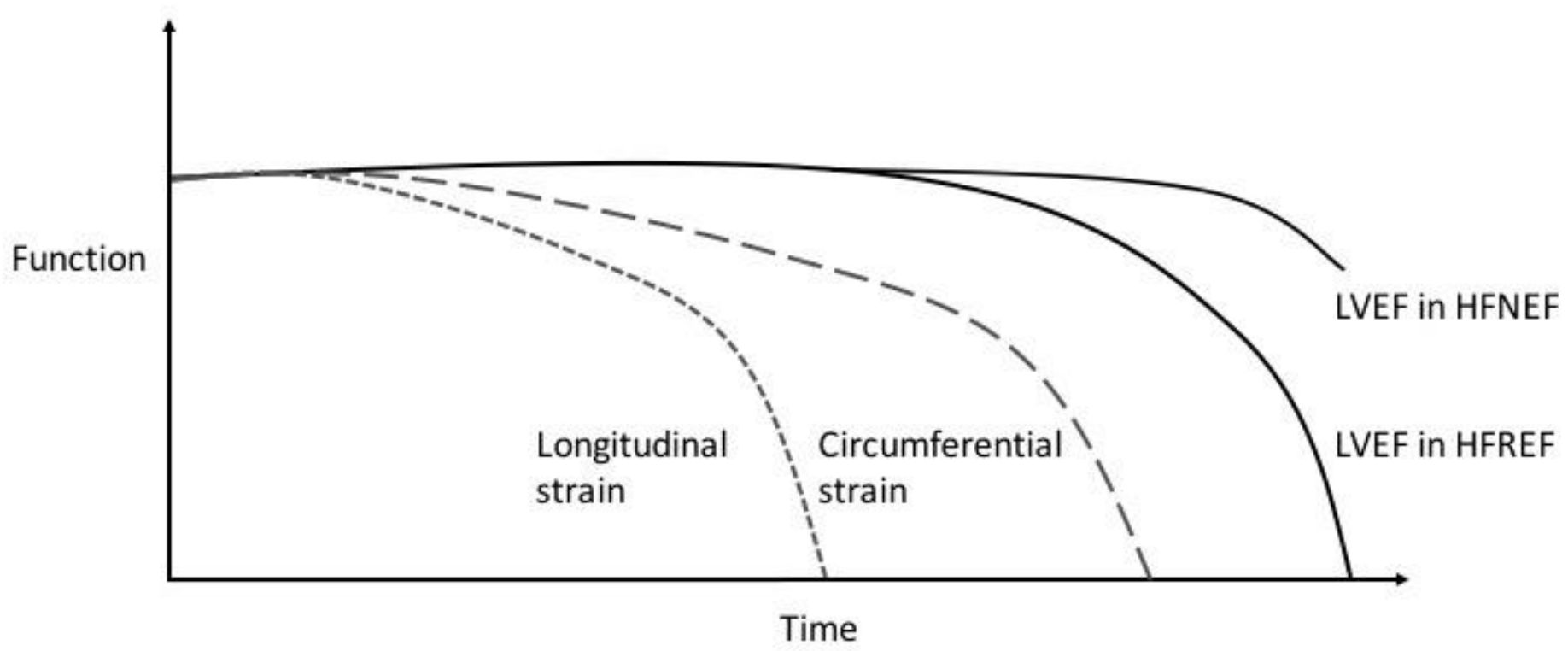

Figure 1 Strain is an early marker of Left Ventricular dysfunction. Abbreviations: LVEF Left Ventricular Ejection Fraction. HFNEF, Heart Failure with Normal Ejection Fraction. HFREF Heart Failure with Reduced Ejection Fraction 


\section{Cardioprotective strategies and HD-associated cardiomyopathy}

\section{Extended dialysis}

Ultrafiltration volumes, ultrafiltration rates and inter-dialytic weight gains can be reduced by extended length or more frequent HD. In this issue, Dr Flythe discusses ultrafiltration strategies and the interaction with intradialytic hypotension in detail. In a cross-sectional study with wellmatched comparator groups, more frequent daily dialysis and nocturnal dialysis were associated with a lower incidence of intra-dialytic LV dysfunction (54). In the Frequent Hemodialysis Network trial, 245 patients were randomized to six or three-times weekly HD (55). After one year, frequent $\mathrm{HD}$ resulted in a significant reduction of $\mathrm{LV}$ mass $(-14 \mathrm{~g} 95 \% \mathrm{Cl},-22$ to $-6 \mathrm{~g})$ and the authors noted that reduced inter-dialytic weight gains may have been a key factor. Intradialytic cardiac imaging was not performed but there was reduced frequency of intra-dialytic hypotension. The ACTIVE study investigators will soon report outcomes from a 200 patient RCT of extended or standard HD for 12 months with a primary outcome of quality of life and secondary outcome of LV mass (clinicaltrials.gov Identifier NCT00649298). Whilst frequent HD is a promising strategy to regress LV hypertrophy, it is resource intensive and may not be universally acceptable to patients nor feasible in all healthcare systems. Simple, low cost interventions that reduce intra-dialytic cardiac dysfunction and HD-associated cardiomyopathy within the constraints of conventional thrice weekly HD schedules are of value.

\section{Dialysate composition}

In a short-term randomized crossover observational study we reported reduced intra-dialytic cardiac dysfunction using a biofeedback technique that modulates dialysate sodium and ultrafiltration rates in response to relative blood volume (56). This is promising but requires 
specialized equipment that discourage larger trials or clinical use. Individualizing dialysate sodium alone might reduce intra-dialytic cardiac dysfunction in the short-term and prevent or regress cardiomyopathy in the long-term. Recent observational data suggest that facility levels of dialysate calcium are associated with intradialytic hypotension and heart failure hospitalization further supporting a rationale for individualized dialysate prescription (57). The long-term effects of lower dialysate sodium on cardiomyopathy are subject to a current RCT with a primary outcome of LV mass (58).

\section{Cooler dialysate}

Intradialytic hypotension is independently associated with mortality whilst intra-dialytic myocardial stunning is reduced by cooler dialysate. The reduction in intradialytic hypotension by cooling the dialysate was first demonstrated by the pioneering work of Maggiore who showed that the superior hemodynamic stability associated with isolated ultrafiltration was entirely mediated through lower temperature in the extra-corporeal circuit (59). A retrospective observational study of 910 patients suggests that lower temperature dialysis was associated with reduced hazard for all-cause mortality. A recent systematic review of cooler dialysate analyzed 26 RCTs with 484 patients (60). Compared with standard temperature dialysis, cooler dialysis reduced the rate of intradialytic hypotension by $70 \%(95 \% \mathrm{Cl}, 49-89 \%)$ with no change in small solute clearance. Confidence in the estimates was limited by small sample sizes, attrition and a lack of appropriate blinding with no trial reporting long-term outcomes (60). We recently reported significant longerterm cardiac benefits of cooler dialysate in a RCT of 73 patients new to conventional 4 hours, thrice weekly, in-center HD. After 12 months, LV mass index was reduced by $15 \mathrm{~g}$, LV dilation was reduced, systolic and diastolic function was preserved, aortic distensibility was preserved and there was no change in the LV ejection fraction (61). The magnitude of cardiac benefits was similar to those seen in the Frequent Hemodialysis Network trials but without resource or time implications. Improved intradialytic hemodynamics represents one of several mechanisms by 
which cooler dialysate might prevent worsening of cardiomyopathy. Pre-clinical data supports that lower temperatures protect cardiac myocytes from ischemic injury through multiple pathways (62). The protective effects of cooler dialysate are likely to extend to other vulnerable vascular beds. We recently reported that cooler dialysate protected patients from ischemic brain injury over 12 months (63). Given the low cost, simple delivery and potential benefits, a larger RCT of cooler dialysate with a primary composite outcome of mortality and major cardiovascular events is in recruitment (clinicaltrials.gov Identifier: NCT02628366).

\section{Ischemic conditioning}

Augmenting protective responses to ischemia might be a potent way to reduce intra-dialytic cardiac dysfunction. Remote ischemic preconditioning (RIPC) by brief episodes of sub-lethal ischemia and reperfusion in a remote organ induces a state of protection from subsequent prolonged myocardial ischemia-reperfusion injury. In phylogenetic terms, RIPC is likely to be an ancient protective response as it is ubiquitous in tissues and highly conserved across species. There are 2 phases of protection; the early phase, within minutes of the preconditioning stimulus for up to 4 hours and a so-called 'second window', 24 hours after the preconditioning stimulus, lasting for around 72 hours. How this benefit is mediated remains to be fully elucidated but involves induction of intracellular kinases and changes in mitochondrial function (64). The preconditioning signal is spread systemically by neurohumoral mechanisms with some mediators identified but several undiscovered. The protective response of RIPC can be mimicked by augmenting some of these mediators (65). RIPC can be induced simply by applying a blood pressure cuff to a limb for 5 minutes or more at greater than systolic pressure. This has proven to be safe with encouraging results for cardiac and renal protection in several smaller studies reporting surrogate outcomes. Two recent landmark multi-center RCTs of more than 3000 patients suggest no difference in cardiac or renal outcomes between RIPC and sham treatment 
in cardiac surgery $(66,67)$. This should not discourage investigation of RIPC in HD patients. The latter studies describe a surgical context confounded by the competing effects of anesthetics (attenuating protection) and opiates (augmenting protection) as well as partial preconditioning by other drugs (68). RIPC remains untested in the setting of HD-associated cardiomyopathy, a unique model of a repetitive myocardial ischemic injury (69). Some investigators consider that beneficial cardiac ischemic conditioning and adverse cardiac stunning represent opposite ends of a continuum of adaptive responses to ischemia (70). Patients using HD lie somewhere on this dynamic continuum. Thus, translating RIPC to the setting of HD warrants studies to establish natural history, proof-of-principle, dose-response and tachyphylaxis leading to appropriately powered RCTs. Novel imaging techniques allowing repetitive interrogation of oxygenation and perfusion may facilitate such studies (47).

\section{Conclusion}

An emerging picture casts conventional HD as capable of inducing a repetitive multi-organ ischemia-reperfusion injury. This was first recognized as intra-dialytic cardiac dysfunction. This may be a key factor in the high mortality in the first year of $\mathrm{HD}$ and the failure of many drug therapies to impact on cardiovascular mortality. Simple, safe and low cost interventions that are universally applicable might avoid the complexity and cost of identifying intra-dialytic cardiac dysfunction. Combining preventive with protective strategies is rational. As the evidence base for novel therapeutic strategies matures, HD may undergo a shift in focus from the empirical delivery of solute clearance to a personalized therapy that balances solute and fluid removal with microvascular protection. Such protective strategies may benefit the heart, brain, gut and residual kidney function with potential impacts on symptoms and quality of life. 


\section{References}

1. Herzog CA, Shroff GR: Atherosclerotic Versus Nonatherosclerotic Evaluation: The Yin and Yang of Cardiovascular Imaging in Advanced Chronic Kidney Disease*. JACC: Cardiovascular Imaging 7: 729-732, 2014

2. Lukowsky LR, Kheifets L, Arah OA, Nissenson AR, Kalantar-Zadeh K: Patterns and predictors of early mortality in incident hemodialysis patients: new insights. Am J Nephrol 35: 548-558, 2012

3. Mclntyre CW, Goldsmith DJ: Ischemic brain injury in hemodialysis patients: which is more dangerous, hypertension or intradialytic hypotension? Kidney Int 87: 1109-1115, 2015

4. McIntyre CW, Harrison LE, Eldehni MT, Jefferies HJ, Szeto CC, John SG, Sigrist MK, Burton JO, Hothi D, Korsheed S, Owen PJ, Lai KB, Li PK: Circulating endotoxemia: a novel factor in systemic inflammation and cardiovascular disease in chronic kidney disease. Clin J Am Soc Nephrol 6: 133-141, 2011

5. Caplin B, Kumar S, Davenport A: Patients' perspective of haemodialysis-associated symptoms. Nephrology Dialysis Transplantation 26: 2656-2663, 2011

6. Park M, Hsu C-y, Li Y, Mishra RK, Keane M, Rosas SE, Dries D, Xie D, Chen J, He J, Anderson A, Go AS, Shlipak MG, Chronic Renal Insufficiency Cohort Study G: Associations between Kidney Function and Subclinical Cardiac Abnormalities in CKD. Journal of the American Society of Nephrology : JASN 23: 1725-1734, 2012

7. Cai Q-Z, Lu X-Z, Lu Y, Wang AY-M: Longitudinal Changes of Cardiac Structure and Function in CKD (CASCADE Study). Journal of the American Society of Nephrology, 2014

8. Eckardt KU, Scherhag A, Macdougall IC, Tsakiris D, Clyne N, Locatelli F, Zaug MF, Burger HU, Drueke TB: Left ventricular geometry predicts cardiovascular outcomes associated with anemia correction in CKD. J Am Soc Nephrol 20: 2651-2660, 2009 
9. Zoccali C, Benedetto FA, Mallamaci F, Tripepi G, Giacone G, Stancanelli B, Cataliotti A, Malatino LS: Left ventricular mass monitoring in the follow-up of dialysis patients: prognostic value of left ventricular hypertrophy progression. Kidney Int 65: 1492-1498, 2004

10. Krishnasamy R, Isbel NM, Hawley CM, Pascoe EM, Leano R, Haluska BA, Stanton T: The association between left ventricular global longitudinal strain, renal impairment and allcause mortality. Nephrology Dialysis Transplantation, 2014

11. Kehat I, Molkentin JD: Molecular pathways underlying cardiac remodeling during pathophysiological stimulation. Circulation 122: 2727-2735, 2010

12. Parfrey PS: Why does the treatment of anaemia not improve cardiac outcomes in CKD? Nat Rev Nephrol 9: 59-61, 2013

13. Goldsmith D, Covic A: Blood pressure control in CKD stage 5D patients-are we more or less certain what to do in 2009? Nephrology Dialysis Transplantation 24: 3597-3601, 2009

14. Odudu A, McIntyre C: Volume is not the only key to hypertension control in dialysis patients. Nephron Clin Pract 120: c173-177, 2012

15. Machek P, Jirka T, MoissI U, Chamney P, Wabel P: Guided optimization of fluid status in haemodialysis patients. Nephrology Dialysis Transplantation 25: 538-544, 2010

16. Glassock RJ, Pecoits-Filho R, Barberato SH: Left ventricular mass in chronic kidney disease and ESRD. Clin J Am Soc Nephrol 4 Suppl 1: S79-91, 2009

17. Siedlecki AM, Jin X, Muslin AJ: Uremic cardiac hypertrophy is reversed by rapamycin but not by lowering of blood pressure. Kidney international 75: 800-808, 2009

18. Lumiaho A, Pihlajamaki J, Hartikainen J, Ikaheimo R, Miettinen R, Niemitukia L, Lampainen $\mathrm{E}$, Laakso M: Insulin resistance is related to left ventricular hypertrophy in patients with polycystic kidney disease type 1. Am J Kidney Dis 41: 1219-1224, 2003 
19. Semple DJ, Bhandari S, Seymour AM: Uremic cardiomyopathy is characterized by loss of the cardioprotective effects of insulin. American journal of physiology Renal physiology 303: F1275-1286, 2012

20. Brutsaert DL: Cardiac Endothelial-Myocardial Signaling: Its Role in Cardiac Growth, Contractile Performance, and Rhythmicity. Physiological Reviews 83: 59-115, 2003

21. Kao MP, Ang DS, Gandy SJ, Nadir MA, Houston JG, Lang CC, Struthers AD: Allopurinol benefits left ventricular mass and endothelial dysfunction in chronic kidney disease. $J$ Am Soc Nephrol 22: 1382-1389, 2011

22. Zoccali C, Mallamaci F, Maas R, Benedetto FA, Tripepi G, Malatino LS, Cataliotti A, Bellanuova I, Böger R, on behalf of The Creed I: Left ventricular hypertrophy, cardiac remodeling and asymmetric dimethylarginine (ADMA) in hemodialysis patients. Kidney International 62: 339-345, 2002

23. Visser M, Paulus WJ, Vermeulen MA, Richir MC, Davids M, Wisselink W, de Mol BA, van Leeuwen PA: The role of asymmetric dimethylarginine and arginine in the failing heart and its vasculature. Eur J Heart Fail 12: 1274-1281, 2010

24. Kukreja RC, Salloum FN, Das A: Cyclic guanosine monophosphate signaling and phosphodiesterase-5 inhibitors in cardioprotection. J Am Coll Cardiol 59: 1921-1927, 2012

25. Stella P, Manunta P, Mallamaci F, Melandri M, Spotti D, Tripepi G, Hamlyn JM, Malatino LS, Bianchi G, Zoccali C: Endogenous ouabain and cardiomyopathy in dialysis patients. Journal of Internal Medicine 263: 274-280, 2008

26. Wolf M: Update on fibroblast growth factor 23 in chronic kidney disease. Kidney Int 82: 737747,2012 
27. Bagrov AY, Fedorova OV: Cardenolide and bufadienolide ligands of the sodium pump. How they work together in $\mathrm{NaCl}$ sensitive hypertension. Frontiers in bioscience : a journal and virtual library 10: 2250-2256, 2005

28. Edwards NC, Steeds RP, Stewart PM, Ferro CJ, Townend JN: Effect of Spironolactone on Left Ventricular Mass and Aortic Stiffness in Early-Stage Chronic Kidney Disease: A Randomized Controlled Trial. Journal of the American College of Cardiology 54: 505512,2009

29. Braunwald E, Kloner RA: The stunned myocardium: prolonged, postischemic ventricular dysfunction. Circulation 66: 1146-1149, 1982

30. Camici PG, Prasad SK, Rimoldi OE: Stunning, hibernation, and assessment of myocardial viability. Circulation 117: 103-114, 2008

31. Bos WJ, Bruin S, van Olden RW, Keur I, Wesseling KH, Westerhof N, Krediet RT, Arisz LA: Cardiac and hemodynamic effects of hemodialysis and ultrafiltration. Am J Kidney Dis 35: $819-826,2000$

32. Zuber M, Steinmann E, Huser B, Ritz R, Thiel G, Brunner F: Incidence of arrhythmias and myocardial ischaemia during haemodialysis and haemofiltration. Nephrol Dial Transplant 4: 632-634, 1989

33. Mclntyre CW, Burton JO, Selby NM, Leccisotti L, Korsheed S, Baker CSR, Camici PG: Hemodialysis-Induced Cardiac Dysfunction Is Associated with an Acute Reduction in Global and Segmental Myocardial Blood Flow. Clin J Am Soc Nephrol 3: 19-26, 2008

34. Dasselaar JJ, Slart RHJA, Knip M, Pruim J, Tio RA, Mclntyre CW, de Jong PE, Franssen CFM: Haemodialysis is associated with a pronounced fall in myocardial perfusion. Nephrol Dial Transplant 24: 604-610, 2009

35. Burton JO, Jefferies HJ, Selby NM, Mclntyre CW: Hemodialysis-induced cardiac injury: determinants and associated outcomes. Clin J Am Soc Nephrol 4: 914-920, 2009 
36. Burton JO, Korsheed S, Grundy BJ, McIntyre CW: Hemodialysis-induced left ventricular dysfunction is associated with an increase in ventricular arrhythmias. Ren Fail 30: 701709, 2008

37. Assa S, Hummel YM, Voors AA, Kuipers J, Westerhuis R, de Jong PE, Franssen CF: Hemodialysis-induced regional left ventricular systolic dysfunction: prevalence, patient and dialysis treatment-related factors, and prognostic significance. Clin J Am Soc Nephrol 7: 1615-1623, 2012

38. Assa S, Hummel YM, Voors AA, Kuipers J, Groen H, de Jong PE, Westerhuis R, Franssen CF: Changes in Left Ventricular Diastolic Function During Hemodialysis Sessions. Am J Kidney Dis, 2013

39. Assa S, Hummel YM, Voors AA, Kuipers J, Westerhuis R, Groen H, Bakker SJL, Muller Kobold AC, van Oeveren W, Struck J, de Jong PE, Franssen CFM: HemodialysisInduced Regional Left Ventricular Systolic Dysfunction and Inflammation: A Crosssectional Study. American Journal of Kidney Diseases 64: 265-273, 2014

40. Kingwell BA, Waddell TK, Medley TL, Cameron JD, Dart AM: Large artery stiffness predicts ischemic threshold in patients with coronary artery disease. Journal of the American College of Cardiology 40: 773-779, 2002

41. Gu H, Sinha MD, Li Y, Simpson J, Chowienczyk PJ: Elevated ejection-phase myocardial wall stress in children with chronic kidney disease. Hypertension 66: 823-829, 2015

42. Hothi DK, Rees L, Marek J, Burton J, McIntyre CW: Pediatric myocardial stunning underscores the cardiac toxicity of conventional hemodialysis treatments. Clin J Am Soc Nephrol 4: 790-797, 2009

43. Hakeem A, Bhatti S, Dillie KS, Cook JR, Samad Z, Roth-Cline MD, Chang SM: Predictive Value of Myocardial Perfusion Single-Photon Emission Computed Tomography and the Impact of Renal Function on Cardiac Death. Circulation 118: 2540-2549, 2008 
44. Mark PB, Patel RK, Jardine AG: Are we overestimating left ventricular abnormalities in endstage renal disease? Nephrol Dial Transplant 22: 1815-1819, 2007

45. Hunold P, Vogt FM, Heemann UW, Zimmermann U, Barkhausen J: Myocardial mass and volume measurement of hypertrophic left ventricles by MRI--study in dialysis patients examined before and after dialysis. J Cardiovasc Magn Reson 5: 553-561, 2003

46. Edwards NC, Moody WE, Chue CD, Ferro CJ, Townend JN, Steeds RP: Defining the Natural History of Uremic Cardiomyopathy in Chronic Kidney Disease: The Role of Cardiovascular Magnetic Resonance. JACC: Cardiovascular Imaging 7: 703-714, 2014

47. Odudu A, Francis ST, Mclntyre CW: MRI for the assessment of organ perfusion in patients with chronic kidney disease. Current opinion in nephrology and hypertension 21: 647654,2012

48. Streeter DD, Jr., Spotnitz HM, Patel DP, Ross J, Jr., Sonnenblick EH: Fiber orientation in the canine left ventricle during diastole and systole. Circ Res 24: 339-347, 1969

49. Eng C, Cho S, Factor SM, Kirk ES: A nonflow basis for the vulnerability of the subendocardium. Journal of the American College of Cardiology 9: 374-379, 1987

50. Odudu A, Eldehni MT, McCann GP, Horsfield MA, Breidthardt T, Mclntyre CW: Characterisation of cardiomyopathy by cardiac and aortic magnetic resonance in patients new to hemodialysis. European radiology, 2015

51. Liu Y-W, Su C-T, Sung J-M, Wang SPH, Su Y-R, Yang C-S, Tsai L-M, Chen J-H, Tsai W-C: Association of Left Ventricular Longitudinal Strain with Mortality among Stable Hemodialysis Patients with Preserved Left Ventricular Ejection Fraction. Clinical Journal of the American Society of Nephrology 8: 1564-1574, 2013

52. Krishnasamy R, Isbel NM, Hawley CM, Pascoe EM, Leano R, Haluska BA, Stanton T: The association between left ventricular global longitudinal strain, renal impairment and allcause mortality. Nephrol Dial Transplant 29: 1218-1225, 2014 
53. Chiu D, Abidin N, Johnstone L, Chong M, Kataria V, Sewell J, Sinha S, Kalra PA, Green D: Novel Approach to Cardiovascular Outcome Prediction in Haemodialysis Patients. Am J Nephrol 43: 143-152, 2016

54. Jefferies HJ, Virk B, Schiller B, Moran J, Mclntyre CW: Frequent hemodialysis schedules are associated with reduced levels of dialysis-induced cardiac injury (myocardial stunning). Clin J Am Soc Nephrol 6: 1326-1332, 2011

55. Chertow GM, Levin NW, Beck GJ, Depner TA, Eggers PW, Gassman JJ, Gorodetskaya I, Greene T, James S, Larive B, Lindsay RM, Mehta RL, Miller B, Ornt DB, Rajagopalan S, Rastogi A, Rocco MV, Schiller B, Sergeyeva O, Schulman G, Ting GO, Unruh ML, Star RA, Kliger AS: In-center hemodialysis six times per week versus three times per week. $N$ Engl J Med 363: 2287-2300, 2010

56. Selby NM, Lambie SH, Camici PG, Baker CS, McIntyre CW: Occurrence of regional left ventricular dysfunction in patients undergoing standard and biofeedback dialysis. Am J Kidney Dis 47: 830-841, 2006

57. Brunelli SM, Sibbel S, Do TP, Cooper K, Bradbury BD: Facility Dialysate Calcium Practices and Clinical Outcomes Among Patients Receiving Hemodialysis: A Retrospective Observational Study. American Journal of Kidney Diseases 66: 655-665, 2015

58. Dunlop JL, Vandal AC, de Zoysa JR, Gabriel RS, Haloob IA, Hood CJ, Matheson PJ, McGregor DO, Rabindranath KS, Semple DJ, Marshall MR: Rationale and design of the Sodium Lowering In Dialysate (SoLID) trial: a randomised controlled trial of low versus standard dialysate sodium concentration during hemodialysis for regression of left ventricular mass. BMC Nephrol 14: 149, 2013

59. Maggiore Q, Pizzarelli F, Zoccali C, Sisca S, Nicolo F, Parlongo S: Effect of extracorporeal blood cooling on dialytic arterial hypotension. Proc Eur Dial Transplant Assoc 18: 597602,1981 
60. Mustafa RA, Bdair F, Akl EA, Garg AX, Thiessen-Philbrook H, Salameh H, Kisra S, Nesrallah G, Al-Jaishi A, Patel P, Patel P, Mustafa AA, Schünemann HJ: Effect of Lowering the Dialysate Temperature in Chronic Hemodialysis: A Systematic Review and Meta-Analysis. Clinical Journal of the American Society of Nephrology, 2015

61. Odudu A, Eldehni MT, McCann GP, Mclntyre CW: Randomized Controlled Trial of Individualized Dialysate Cooling for Cardiac Protection in Hemodialysis Patients. Clinical Journal of the American Society of Nephrology, 2015

62. Tissier R, Ghaleh B, Cohen MV, Downey JM, Berdeaux A: Myocardial protection with mild hypothermia. Cardiovascular Research 94: 217-225, 2012

63. Eldehni MT, Odudu A, Mclntyre CW: Randomized clinical trial of dialysate cooling and effects on brain white matter. J Am Soc Nephrol 26: 957-965, 2015

64. Hausenloy DJ, Yellon DM: Remote ischaemic preconditioning: underlying mechanisms and clinical application. Cardiovasc Res 79: 377-386, 2008

65. Downey JM, Cohen MV: Why do we still not have cardioprotective drugs? Circ J 73: 11711177,2009

66. Meybohm P, Bein B, Brosteanu O, Cremer J, Gruenewald M, Stoppe C, Coburn M, Schaelte G, Boning A, Niemann B, Roesner J, Kletzin F, Strouhal U, Reyher C, LaufenbergFeldmann R, Ferner M, Brandes IF, Bauer M, Stehr SN, Kortgen A, Wittmann M, Baumgarten G, Meyer-Treschan T, Kienbaum P, Heringlake M, Schon J, Sander M, Treskatsch S, Smul T, Wolwender E, Schilling T, Fuernau G, Hasenclever D, Zacharowski K: A Multicenter Trial of Remote Ischemic Preconditioning for Heart Surgery. N Engl J Med 373: 1397-1407, 2015

67. Hausenloy DJ, Candilio L, Evans R, Ariti C, Jenkins DP, Kolvekar S, Knight R, Kunst G, Laing C, Nicholas J, Pepper J, Robertson S, Xenou M, Clayton T, Yellon DM: Remote Ischemic Preconditioning and Outcomes of Cardiac Surgery. N Engl J Med 373: 14081417, 2015 


\section{Intradialytic Cardiac Dysfunction}

68. Przyklenk K: Ischaemic conditioning: pitfalls on the path to clinical translation. $\mathrm{Br} J$ Pharmacol 172: 1961-1973, 2015

69. Crowley LE, McIntyre CW: Remote ischaemic conditioning-therapeutic opportunities in renal medicine. Nat Rev Nephrol 9: 739-746, 2013

70. Futterman L, Lemberg L: Hibernating myocardium, stunning, ischemic preconditioning: clinical relevance. American Journal of Critical Care 9: 430-436, 2000 